\title{
Policy networks as a unit of analysis of public policies a case study of the social and health insurance policy network in Egypt (2015-2019)
}

\author{
Hasan Saber and Salwa Shaarawy Gomaa \\ Faculty of Economics and Political Science, Cairo University, Giza, Egypt
}

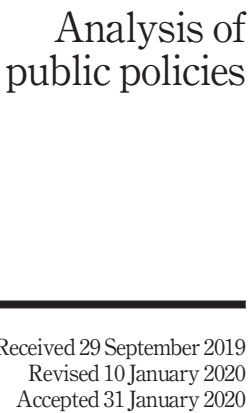

\begin{abstract}
Purpose - This study aims to explain the emergence and development of the concept of "Policy Networks" as a unit of analysis in the realm of public policies and their role in formulating a comprehensive policy for health insurance. The developments that took place over the past few decades had impacted a shift in the state's role in shaping public policies, from a sole, key actor to one among other actors, both governmental and non-governmental, working interdependently through a set of networks.

Design/methodology/approach - The present study adopts the social network analysis as an approach and the social policy network as a tool to analyze public policymaking. The approach suggests the presence of a number of actors and interest groups that are actively involved in public policy and decision-making. These groups may vary from a cause to another and also from time to time. This research investigates and juxtaposes a selected sample of members of the health insurance policy network in Egypt.

Findings - In light of the study findings, one can see the existence of a policy network for the comprehensive health insurance system in Egypt. The study reveals the interrelations among a number of official and non-official key actors. The network has gone through several phases; the pre-establishment phase during the early stages of policymaking; the official establishment phase during the formative stage; and finally, the network operation phase during the implementation stage. The study also concludes that the policy network has influenced the different stages of policymaking through several tools and strategies. Moreover, the roles of different actors varied within the network; international organizations were the primary influencer in the early stages of policymaking; syndicates dominated the formative stage; and the public sector played the leading role in the implementation stage.

Research limitations/implications - Serious attempts were made to benefit from policy networks with a particular focus on using the strengths of each actor while establishing an official institutional framework that consolidates coordination and cooperation among the involved parties. This framework should keep pace with global changes and developments. It should also have an official meeting venue. Above all, all parties should be listened to and their demands should be considered seriously as long as they are not actualized at the expense of the public interest nor do they undermine the sovereignty of the state. The study also enhances researchers to use policy networking as a unit for analyzing public policy and their effect on these policies.
\end{abstract}

(C) Hasan Saber and Salwa Shaarawy Gomaa. Published in Review of Economics and Political Science. Published by Emerald Publishing Limited. This article is published under the Creative Commons Attribution (CC BY 4.0) license. Anyone may reproduce, distribute, translate and create derivative works of this article (for both commercial and non-commercial purposes), subject to full attribution to the original publication and authors. The full terms of this license may be seen at http:// creativecommons.org/licences/by/4.0/legalcode
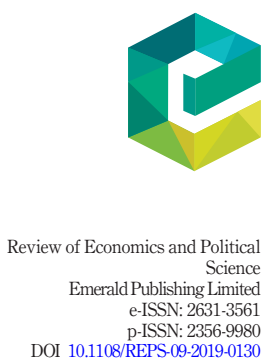
Practical implications - Public policymaking in Egypt can become more responsive to people's demands and more democratic once it was made through informative and interactive policy network. This pattern of policymaking will enhance both efficient and responsive.

Social implications - Practical Implications: public policy making in Egypt can become more responsive to people demands and more democratic once it was made through informative and interactive policy network. This pattern of policymaking will enhance both efficient and responsive.

Originality/value - In addition to its practical contributions to the field of policymaking, this research fills a gap in the literature on the theoretical level.

Keywords Policy network, Health insurance, Public policies, Actors

Paper type Research paper

\section{Introduction}

The world has witnessed rapid developments since the 1990s in many areas, whether political, economic or social, which were accompanied by the emergence of many new terms and concepts such as globalization, governance, terrorism, etc. These developments have changed the role of the state and thus, new trends in government administration and reinvention and in managing the affairs of state and society have existed. Moreover, as the role of the state changed, its level of interaction with new actors such as the private sector, civil society organizations and international organizations has increased. Interdependence was maximized and came to play a significant role in shaping public policies. Several studies consider public policies as the outcome of formal and informal interactions among a number of actors at the local and central level. They also perceive public policies as an outcome of the interplay of those actors who are usually members of an organized network or what has come to be known as "policy networks" (Gomaa, 2004, p. 31).

Health insurance policies are deemed one of the main pillars of the society and an essential basis for its stability and satisfaction, especially, as the development and prosperity of a society cannot be achieved independently of an effective system of health care. Therefore, these policies received considerable attention from both the state and those who are concerned with health issues. Since the mid-1990s and after the deterioration of health services, there have been frequent attempts to reform the health system in Egypt, especially with the support of donor entities and the emergence of a number of new actors such as international organizations, the private sector and civil society organizations working in the health sector. The mutual influence enabled these actors - by working together within a network of social health insurance policies - to have a prominent role in the policymaking process. Although Law No. 2 of 2018 on comprehensive health insurance has been enacted and put into effect, scant studies examined the lawmaking and the impact of policy networks on its development. The available studies, however, focused on health insurance policies with regard to public satisfaction, outsourcing, funding, restructuring, etc. To fill this gap in research, this study attempts to investigate the impact of policy networks on the making of comprehensive health insurance law in Egypt.

\section{Research problem}

Although there are many actors in the field of health policies in Egypt, the state; the private sector; civil society organizations; and international organizations, and despite the interactive relations among them that make them work together within the framework of a policy network, there is considerable controversy over what this network is and how it affects the stages of policymaking. In this sense, the research problem lies in the main 
question about the emergence and evolution of the concept of social, health insurance policy network in Egypt and its impact on the stages of health insurance policymaking?

\section{Research questions}

The main research question will be branched into the following subquestions:

RQ1. Is there a social/health insurance policy network in Egypt? How did this network evolve?

$R Q 2$. How did the policy network affect the stages of health insurance policymaking in Egypt?

RQ3. What are the most important recommendations through which we can benefit from these networks in the development of the health sector?

\section{Literature review}

Through a review of the literature, one can address these studies and their outcomes in the light of two underlying concepts, "networks" and "health insurance." Several studies analyzed the concept of "network" from different perspectives. It first appeared after the technological revolution being used in the field of electrical engineering to express the complex relations and connections among the involved components and their functions as in information, telephone and computer networks. Then the concept found its way through other sciences and disciplines. Electronically speaking, a network is:

[...] a system in which a number of independent computers are connected to each other so that they can use the same data and other physical components such as hard disks and other sources (El-Shafei, 2002).

Others define it as:

[...] two or more remotely connected entities governed by many protocols that control data congestion through terminal systems and by sending data packs from the sender to the receiver. These protocols also direct and designate the course that each pack should follow from the source to its destination, whether on the Internet or a local network. (Ross, 2006)

These studies surveyed the concept of network and its various components such as internet software in particular and computer networks in general. Since the 1980s, studies identified their most important types and ways to protect them from cyber-attacks. Finally, other studies focused on the concept through studying the basics of computer networks and pointing out to the prominent systems and applications available for data transfer such as open systems and data communication systems. Later, the study covered network cards, electronic complexes and their relation to the protocols responsible for transferring data within the network (El-Hussaini, 2009) .

Afterward, the concept of "networks" was used in the field of social work to refer to a group of individuals, institutions or organizations seeking to achieve specific goals. As such, a sociological perspective was introduced by studying the impact of social safety networks on poverty. These networks were divided into several networks including "food and production" to demonstrate their impact and the need to strengthen social safety network programs and further their effectiveness. (Saleh, 2016). Others applied the same concept of "social safety networks" studying its impact on the system of social insurance and benefiting from the experiences of other countries, effectiveness in achieving their political, economic and social objectives. These studies concluded that the absence of comprehensive
Analysis of public policies 
policies of social security would have a negative impact on society (Ibrahim, 2015). From the same sociological perspective, some studies dealt analytically with the network of social protest movements as access to understanding political changes and how to build alliances between formal and informal actors to influence political decision-making (Abd Rabbo, 2015). Finally, other studies have focused on the non-governmental organizations (NGO) networks through the same perspective. Its role becomes not only a backer but also a partner of the government and the private sectors. This acts to respond to the unfulfilled social and economic needs that neither of them can do (Shteh, 2004).

The concept of network then introduced to the domain of political and administrative work in the context of a public policy network using it as a unit for policy analysis. Dr Salwa Shaarawy Gomaa is deemed the first to address the concept of the network as a unit for analysis and development of public policies in the Arab world through four main axes: the analysis unit, policy issues and content, methodology of analysis and intellectual schools. She pinpointed a change in the public policy analysis unit. The focus has shifted from the state and its institutions in the 1970s to emerging new actors such as multi-national companies, international organizations, international NGOs and the public sector. There have been many trends that see public policies as the outcome of formal and informal interactions between a number of actors at the local and central levels. They also argued that public policies are the result of the interplay of those actors who are usually members of a network or what has become known as a "policy network" (Gomaa, 2004).

Other studies have analyzed the concept of the policy network as a set of concepts that focus on governance links through the interdependence of actors that influence public policies. These concepts include the networking issue, policy sub-systems and knowledge societies. From this perspective, the policy network is defined as "a set of formal and informal institutions with a number of different linkages" (Rhodes, 2006). Many studies dealt theoretically with the concept of policy network in terms of its definition, importance and types as well as its relation to changing the contemporary world and its impact on the concept of power in international relations. A series of political and economic changes have led to the emergence of new actors in a networked world where actors are aware that their distances are approaching, and their issues are overlapping. Such complicated interrelations limit the ability to lead this world centrally or control the complex interactions even by the major powers that dominate the balance of power in the world (Hanafi, 2015). This review of the literature shows that previous studies applied the term "network" to the electronic devices or individuals in the community or on any party of the policy network and, thus, the present study uses the term differently.

The second type of literature reviewed in this study dealt with the policies of social health insurance. It is noticeable that the new insurance policy law changed the term "social" to "comprehensive," unlike previous laws that only included state employees and their siblings, it accommodates all social groups. Moreover, the new law covers "all diseases" but excludes general health services, emergency services and family planning services as they are considered services that the state is committed to provide free of charge to all citizens. The new law detached funding from the process of providing the service itself by creating three independent, yet connected, authorities. The first is the Health Care Authority responsible for the service delivery outlets. The second is the Quality and Accreditation Authority that grants hospitals accreditation in accordance with certain quality standards. The third is the Health Insurance Authority that manages and finances health insurance. This law is to be implemented through six phases over a period of 15years (2018-2032), with each phase covering five governorates. Since the enactment of the law, no study has ever attempted to analyze the pre-formulation and formulation stages as the present study does. For example, 
many studies focused on outsourcing as a tool for improving performance in public organizations. By applying the idea on health insurance, they argued that the effective application of outsourcing is closely linked to increasing the efficiency of the administrative apparatus (Al-Zoghbi, 2008). Other studies focused on assessing the overall service satisfaction as an entry to the development of public organizations by applying certain standards to the General Authority for Health Insurance. Among the applied standards was the quality of service as an approach and philosophy governing the work of public organizations whose ultimate purpose is to increase citizens' satisfaction with the services provided to them (AlZoghbi, 1998). Other studies paid particular attention to the economy of health-care programs. This was done through a survey of the evolution of health-care programs in Egypt and the features of health reform that the international organizations imposed in the second half of the 1990s. These studies also included current problems that impede health services as well as the limitations of the current health care plans, emphasizing the importance of considering the social aspect while providing these services (Ebid, 2004). Finally, other researchers focused on public health policies and strategies and funding mechanisms in this sector and how the decisions are made within. To do so, their research shed light on the functions and activities of the United States Agency for International Development (USAID) and their impact on the health sector and program evaluation through efficiency indicators. They concluded that there is considerable reliance on the USAID, poor systematic planning and lack of funding structures to administer health programs (Peter, 1997).

\section{Social, health insurance policy network in Egypt}

The role of the state in decision-making has been recently changing with the emergence of several forces involved in shaping policymaking including the private sector and national and international NGOs. Thus, bureaucracy is one among many actors in a framework of network relations. This had to be accompanied by a change in the classical concept of the public organization within the broader concept of what is known as the "virtual state" (Elwani, 2010, p. 95).

In an attempt to answer the question of whether there is a health insurance policy network in Egypt or not, the researcher extracted the following indicators from the different definitions of the concept of policy networks to rely on in this pursuit:

- The existence of more than one influential actor in the formulation of social and health insurance policies in Egypt, official or non-official.

- The existence of entwined relations among these actors, whether they are reciprocal, interdependent or cooperative relation "partnership of all kinds, information exchange, funding, oversight, etc.” (Compston, 2009, p. 7).

There is a large number of influential actors in health insurance which are limitless. Although some studies identified them as 29 influential actors in public health policymaking in Egypt, both official and non-official (Abdel Fattah, 1993, p. 25), the researcher finds it difficult to designate them because of their constant change from a place to another and from time to time according to the policy understudy. Therefore, one can say that health insurance policy network in Egypt consists of official actors, the state and its institutions and nonofficial actors, the private sector; civil society organizations; and international organizations.

\subsection{Official actors in the social and health policy network in the Egyptian constitution of 2014} These are the legitimate channels without which the network cannot exist. They include the state's institutions in charge of developing, implementing and evaluating policies.
Analysis of public policies 
According to Article 18 of the 2014 Constitution, access to health care is the right of all citizens. In this sense, the following institutions are considered the key actors:

- The Executive Authority: It includes individuals working in the governmental bureaucracy of various institutions, bodies, committees and administrative units, which often carries out the implementation of general health policies - the Ministry of Health and Population, the General Authority for Health Insurance and the Authority of Educational and University Hospitals.

- The Cabinet: Through government policies and directives on different societal issues as well as bills, the government refers to the parliament. These bills often reflect multiple political alignments that take place before and during passing the law.

- The legislative institution: The legislature is deemed one of the most important state's institutions whose primary role is enacting laws and the establishment of general rules governing the various political, economic, social, health and other aspects of societal life According to the 2014 Constitution, Article 101 sets the parliament to be the sole authority entitled with upholding the general policies of the state (Article 101, Constitution of 2014).

\subsection{Non-official actors in the policy network of social and health insurance Egypt}

Non-official actors are independent parties that influence health insurance policies. Despite the fact that neither the constitution nor the domestic laws state a certain role for them, Article 18 of the 2014 Constitution emphasizes the participation of both the private sector and civil society in health services. Among the most important non-official actors are:

5.2.1 Private sector. The private health sector includes hospitals, clinics and private pharmaceutical companies owned by an individual or a group of individuals who manage or hire someone to run it, whether professionals or not, for the purpose of making profits (AlJinaidi, 2007, pp. 140-142). Information about the status of the private health sector in Egypt is scarce. According to the Ministry of Health, there were 1,422 private health units in 2013, with a total number of beds that reached 32.6000 , representing $25 \%$ of hospital capacity in Egypt. In addition, there were more than 90,000 private clinics across the governorates (Ministry of Health, 2017 website). As the number of treatment facilities has increased, a report issued by the Central Agency for Public Mobilization and Statistics revealed an increasing number over the past years (Table 1).

There is a statistical problem with the number of workers in the health sector and whether they work at state service centers or not. The Central Agency for Public Mobilization and Statistics 2019 report also indicates a constant growth in the number of doctors working in the private sector (Table 2):

Table 1.

Number of treatment facilities has increased from 2016 to 2017

\begin{tabular}{lrr}
\hline Eears & & \\
\hline Eotal establishments & 2016 & 2017 \\
Government sector & 7,189 & 7,294 \\
Private sector (including hospitals and clinics) & 5,732 & 5,764 \\
& 1,457 & 1,530
\end{tabular}

Source: Central Agency for Public Mobilization and Statistics Report 2019 
5.2.2 Civil society. The civil society represents a group of voluntary organizations which are committed to certain values of respect, conformity and sound management of diversity and difference providing services, otherwise not provided by the state to achieve collective benefits to the society. According to the general union of NGOs, there is an estimated number of 14,979 organizations concerned with health and population (Kandil, 2015, p. 17) (Table 3).

5.2.3 International organizations. Interest in public policies in the global system had begun before the creation of the United Nations and manifested itself in organizations such as the International Labor Organization and the World Health Organization (WHO), among other entities. This comes in the context of interest in various developmental areas. The 1990s witnessed a tendency toward developing international policy at various levels. The series of global conferences held during that period paved the way for the crystallization of frameworks which focus on specific areas. The beginning was the "Health for All" initiative, launched in the late 1970s, which was followed by the Child Health Conference in 1990 and the 1994 Conference on Population and Development and other subsequent international conferences (Abdul Aziz, 2004, p. 221).

It is noted that there are reciprocal relationships among all parties in the network as there are also differences in the form of the sub-networks and the form of the umbrella policy network of social health insurance under which they all get together. The form of the network within official institutions is often hierarchical, while the form of the network in international organizations depends on the main organization and its charts and subsidiaries. The form of the private sector network, on the other hand, is characterized by interdependence, whereas the civil society is based on cooperation among workers in the same field. The form of the health insurance policy network and the form of each network within the involved parties can be illustrated in Figure 1.

The burdensome commitments of the state coupled with an inefficient provision of public service and infrastructure lead several countries to resort to international organizations for funding and to partnership with the private sector. The idea of this should be noted here that the partnership between the state and the private sector is cumbersome, as the latter is profit-oriented while the former seeks to achieve public interests (Salem, 2011, p. 28).

\begin{tabular}{lrrrr}
\hline Enterprise & \multicolumn{2}{c}{2016} & 2017 \\
Total & Nursing staff & No. of doctors & Nursing staff & No. of doctors \\
Government sector & 207,143 & 151,077 & 219,265 & 156,162 \\
Private sector (including hospitals and clinics ) & 187,090 & 123,881 & 191,361 & 124,871 \\
& 20,053 & 27,196 & 27,914 & 31,291
\end{tabular}

Source: Central Agency for Public Mobilization and Statistics Report 2019

\section{Analysis of public policies}

\section{$-$}




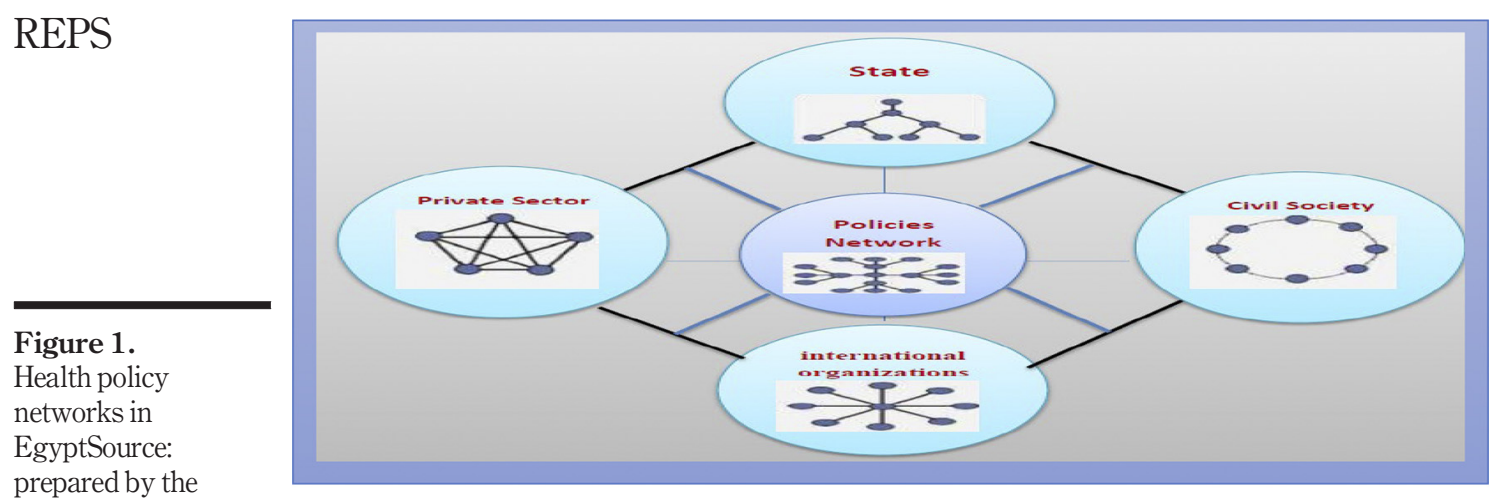

Source: Prepared by the researcher

On the contrary, the relationship between the state and civil society organizations are primarily based on integration, interdependence and distribution of roles, rather than being conflicting or rivalry partnership. Indeed, civil society is the nascent of state power and the balance of its strengths. Thus, the Egyptian Constitution of 2014 (Article 75) emphasized the freedom of establishing civil associations and organizations. Nonetheless, there have been constant tensions in this relation between the state and civil society tensions that are often ascribed to foreign funding and alleged attempts to impose international agendas.

\section{Role of the policy networks in influencing the phases of making comprehensive health insurance policies in Egypt}

The early stages in formulating public policies are the most critical, as it poses issues and problems and determine their place on the government's agenda by presenting societal problems that dictate interference and proper policies to address them. But for an issue to be present on the agenda and subsequent action plans, the government prioritizes many issues according to some factors. "The sense that the problem affects a wide segment of the society draws the attention of decision makers, international funds or financial resources, and international support or pressure." The necessary and accurate information must be available to identify problems, weaknesses and shortcomings in any political system (Gomaa, 2015).

The formation of the network itself has passed through different stages. At the early phase of comprehensive health insurance, policymaking the network was still under formation. Each party of the network was pursuing their own interests during the early phase of policy introduction and priority setting. The parties then discovered the importance of working collectively for mutual benefit and hence the network moved to the establishment stage. The network began to emerge through the establishment of a national committee that undertakes preparing a bill. The committee included representatives of the government, private sector, civil society organizations working in the health field as well as various unions. The committee was based in the parliament and held about 17 meetings through a joint committee that comprised the Health Affairs, the Planning and Budgeting and the Constitutional and Legislative Affairs committees (joint report, the Joint Committee for the Preparation of the Law in Parliament 2017, p. 3). Each party of the network expressed their opinion and reservations during the drafting stage. Although the World Bank representative did not attend these meetings, a number of meetings were held individually 
with each party to discuss the draft of the Comprehensive Health Insurance law (an interview with Dr Omar Al-Shalakami, Egypt's Health File official at the World Bank). The chairman of the National Committee on the Comprehensive Health Insurance Law believes that the committee is the first of its kind in terms of the number of multiple participants in drafting the bill. Most of the previous laws were drafted solely by the government (an interview with Dr Abdelhamid Abaza, Chairman of the Parliament's Law Preparation Committee).

Before addressing how policy networks influence health policymaking policies, it is important to highlight the government's basic motivations for proposing and prioritizing comprehensive health insurance policies. Several considerations have motivated the Egyptian government to include these policies and place them on the government's agenda, including its attempt to meet the urgent needs of the citizens to achieve their satisfaction. In 2017, the population exceeded 100 million people, which derived the government to realize the importance of the health sector, especially a deteriorating one such as in Egypt. Although $95 \%$ of the populations live within $5 \mathrm{~km}$ where health facilities are located, these facilities provide poor health care to citizens, contributing to the increasing dissatisfaction with the services provided. In addition, international donors also encourage the government to adopt a specific policy through its willingness to provide financial aid such as grants and loans from international organizations - the World Bank and foreign aid programs such as the Canadian Development Agency; Danish Development Agency; and the USAID. The state also tries, through improving the health sector, to abide by international treaties and conventions. Egypt has recognized the principle of the right to health contained in the constitution of the WHO issued in 1946. Therefore, the Egyptian government has to provide adequate service which should be accessible to all people, regardless of their race, religion, political beliefs, economic or social status and in accordance with the conventions and principles of the international community.

Finally, by improving the health sector, the government is seeking to strengthen its international presence by achieving advanced positions in health indicators. The publication of international reports that rank countries according to indicators of health conditions helps governments to identify the areas of great concern and thus encourages them to take an action to improve these conditions. Reports show the ranking of each country in comparison to other countries, and Egypt came among the lowest countries in health services. Likewise, the index of achievement of the basic requirements of health and education dropped in 2016-2017 to place Egypt in the 89th position among 138 countries. For a deeper analysis of the impact of policy networks on the making of comprehensive health insurance policies in the early stages, the role of each actor will be studied individually. This is not to suggest that they work in isolation, but, as noted earlier, that in the formation stage, they reach a formula that the majority of stakeholders in the network may accept.

The present study found that the largest share in the early stages of making health insurance policies is for international organizations. On the top of these organizations are the World Bank and the WHO (World Bank, 2014 website). The WHO and the World Bank have developed a framework to follow up on the progress in achieving the comprehensive health coverage. The framework includes three general indicators: coverage of health services, protection from financial risks and equity or coverage of all population. The purpose of measuring these indicators is to progressively achieve comprehensive health coverage for all countries.

In addition, several international organizations had issued policy-oriented research and reports encouraging various governments to adopt the comprehensive coverage policy. This had a significant impact on the state in the initial stage, setting priorities and placing the 
policy on the political agenda. The Comprehensive Coverage Research Report, for instance, was an efficient tool to send messages to decision-makers about the importance of comprehensive health coverage and its benefits. These messages also pointed out that the comprehensive health coverage cannot be achieved without the use of data derived from research projects that address a wide range of issues (who.int, 2013). The Health Systems Financing Report was also of great importance as it dealt with funding as an essential determinant in the implementation of comprehensive health coverage policies. In this report, the WHO explained how countries can adjust their funding systems to accelerate their advancement toward the comprehensive coverage and to ensure sustainable achievements (who.int, 2010).

International organizations have used technical cooperation tools to put forth issues that allow them to work collaboratively with governments and provide technical and material support to civil society organizations. In this way, they are providing technical support that would have an impact on the issue of comprehensive health insurance. The Assistant Minister of Finance stated that Egypt partners with 10 international development organizations that provide all technical support to the government to boost its efforts in accelerating the implementation of comprehensive social health insurance (Youm7.com, 2016).

In addition to the use of soft power mentioned above to influence the early stages of making comprehensive health insurance policies, international organizations have used hard "binding" force as mandatory international law conventions. Member countries are obliged to present the agreement adopted by the organization before their local authorities to enact legislation. One of the most important steps in this regard was Egypt's signing of the Global Agreement for Achieving Comprehensive Health Coverage for the North and Eastern Mediterranean countries of the WHO in 2018 (Al Ahram, 2008). Egypt also signed an agreement with the World Bank to support the health sector with $\$ 530 \mathrm{~m}$ (worldbank.org, 2018), and another agreement of 308m Euros with the French Agency for Development in 2016 (State Information Service website, 2015). Finally, a protocol of cooperation was signed by the Egyptian government and the African Development Bank to update the actuarial study of drafting a comprehensive health insurance law (akhbarelyom.com, 2014).

Despite the role of international organizations in the early stages of health insurance policymaking, there is a role for the rest of the actors in the network. The private health sector - hospitals, clinics and medical testing centers, private pharmaceutical companies owned by an individual or a group of individuals - played a significant role. They are often represented by different people within the General Federation of Chambers of Commerce. Their management is based on modern administrative, financial and marketing methods in the management and operation of these organizations in pursuit of profit. This sector is deemed one of the most influential parties in policymaking; it is governed by a pattern of financial statements through which the income and expenses are calculated to show the profit and loss over a certain period. They also have systems for budgeting and cost estimation. In one incident, for example, the spokesman of the Division of pharmacy owners warned that they would take to the street if the law being drafted ignores their demands (Elkhabar website, 2016). However, the attendance of representatives of the Chamber of Commerce in the parliamentary meetings to discuss the bill and the positive response to their requests had them change their position. The Division of Pharmacy had a reservation on a number of articles in the draft, but their reservations were taken into consideration, and they were amended accordingly. For example, the payment of 500,000 for any company under construction and 250,000 for annual renewal were amended to $0.5 \%$ of the company's commercial registered capital. However, there are points that have not been addressed and 
left to the implementation stage, such as medicine dispensing policy and pharmacygovernment policy (an interview with Dr Ali Auf, head of the General Division of Medicine and representative of chambers of commerce in the law preparation committee).

The private sector practiced soft power as well to influence the early stages of lawmaking. Several seminars and conferences were held to discuss the impact of the comprehensive health insurance law on the private sector along with providing some suggestions and recommendations to amend the draft law and, indeed, they have had a significant impact on the lawmaking. Among the most important events was a seminar of the Insurance Federation of Egypt in 2013 to discuss the bill (General Union of Insurance Companies, 2013), the annual conference on investment in health care 2017 (Al Arabiya website, 2017) and the Arab Conference on Hospital Management. The conference recommendations included encouraging the private sector to invest in the field of comprehensive health insurance (Sada Elbalad website, 2015). In addition to these seminars, the private sector used the media and news websites to mobilize public opinion through press conferences and statements by officials in an attempt to influence decision-making. Consequently, the government demanded that the private sector be involved in implementing these policies (Al-Akhbar website, 2018).

The private sector also practiced hard power in the form of competition to provide services and attract beneficiaries to get better service. Hence, the government is trying to benefit from the private sector's expertise by involving it in projects and initiating partnerships. To regulate this relation with the private sector, the government has established the Central Unit for Partnership with the Private Sector in the Ministry of Finance. The unit serves as a liaison between the public and private sectors and its primary task is presenting and promoting collaboration policy (Ministry of Finance, 2012).

Despite the impact of each actor within the policy network had during the early stages of making the health insurance policy, they had not formed an official network. Each actor worked independently even though they had many meetings and joint seminars. Later during the policy formulation stage, the policy network was formed and formalized with the creation of the Law Preparation Committee in the parliament. The committee comprised the different parties of the policy network, the Government; the private sector; civil society organizations; and trade unions. While drafting the law, the government took into account the participation of all parties in the network and considered their various reservations to try to come up with a law that represents all strata of society and satisfies most parties while at the same time achieving the general interest of the state (an interview with Dr Wajida Anwar, Head of the Union of Health System Development Associations and member of the Law Preparation Committee). It should be noted here that the largest role in the drafting stage was for the government and later on came the role of the various unions and the private sector.

Port Said witnessed the first trial run during the implementation stage. The researcher noticed considerable interest on behalf of the government during this stage, Later on, this process took place with the participation of different network stakeholders. The opportunity was given to all those who wanted to participate on the condition that they meet the requirements laid down by the Quality Control and Accreditation Authority, including the national safety standards. The state provided the policy network stakeholders with an opportunity for partaking in policy implementation and already contracted with several doctors/physicians, private hospitals/clinics and foreign nurses. The researcher noticed that the private sector is nevertheless watching for the results of the first phase to decide on the amount of investment to be pumped into the policy implementation. He also observed an important role for international organizations, especially through providing funds and technical support. The French Development Agency, for example, supported the law implementation technically through an Egyptian-French partnership. On the 
other hand, the Japanese International Cooperation Agency, in cooperation with the World Bank, funded the comprehensive medical care program with $\$ 250 \mathrm{~m}$ (elgornal.net, accessed June 2019). Therefore, we find that the main role in the implementation phase rests with the government and the private sector. Some believe in the necessity of having various expertise in the fields of management and public policies in the implementation stage to ensure success of this system (an interview with Dr Nabil Amin, former head of the General Authority for Health Insurance).

During the evaluation stage, the government enjoys the primary role through the accreditation and health control authority, one of the bodies of the new comprehensive health insurance system that aims to ensure the quality and continuous improvement of health services (Youm7.com, 2018). The authority also supervises and controls over all medical facilities and members of the medical professions working in the medical services sector, setting quality standards for health services, applying quality standards to medical care facilities, accreditation and registration of medical facilities complying with quality standards, etc.

\section{Conclusion}

There have been many developments over the past decades, both domestically and internationally. These developments were followed by a change in the role of the state from the sole decision-maker to one among other actors in public policymaking. We have seen the existence of multiple actors, whether official or non-official, working through networks. Although there are different definitions and applications of the term "network" in the various disciplines, they all shared two characteristics, a group of parties or node and a set of connections that regulate the internal dynamics of the network. By applying the elements of these definitions to the social and health insurance policy networks in Egypt, it was found that there are many official and non-official actors (the state and its institutions on the one hand, and the private sector, international organizations, civil society organizations on the other) as well as the existence of overlapping and interrelating relations and mutual influence. It is, therefore, possible to argue that there a health insurance policy network in Egypt - a network that emerged in the early stages of policymaking and developed as the law was undergoing its process of enactment. By investigating the role of this network in influencing the making of comprehensive health insurance policies, this study demonstrated the network had used different means to influence public policymaking. It also showed that these means and tools varied from one actor to another in an attempt to achieve the best of their interest. For example, international organizations dominated the early stages of policymaking while the various unions had the greatest impact in the drafting stage. Likewise, the private sector has a greater impact on the implementation stage if they comply with the conditions. Finally, the government's major role in the evaluation phase is practiced through the Quality Control and Accreditation Authority.

\section{Findings and key recommendations}

\subsection{Present study has presented the following key findings}

- The existence of health insurance policy network in Egypt. The network comprises both official and non-official actors working together interdependently. This network has evolved from the pre-formulation phase during the first stage of policymaking to the formulation phase during the drafting stage, and then to the network's operation phase during the policy implementation stage.

- There is an impact of these networks on shaping health insurance policies through a number of mechanisms and tools such as grants, loans, aids, policy-oriented studies, media and mobilization of public opinion and promotion of policies, seminars and conferences, statistics and international reports and indexes. 
- Despite the fact that numerous laws have been issued in favor of the health sector, yet some indications show that Egypt's place had deteriorated on the international competition index from 99 in 2018 to 103 in 2019. The problem lies in the implementation phase, because the policy network is alienated from both implementation and the evaluation stage of the services provided to citizens.

\subsection{Study recommendations}

Serious attempts were made to benefit from policy networks with a particular focus on using the strengths of each actor while establishing an official institutional framework that consolidates coordination and cooperation among the involved parties. This framework should keep pace with global changes and developments. It should also have an official meeting venue. Above all, all parties should be listened to and their demands should be considered seriously as long as they are not actualized at the expense of the public interest nor do they undermine the sovereignty of the state. The study also enhances researchers to use policy networking as a unit for analyzing public policy and their effect on these policies

\section{References}

Abdul Aziz, H. (2004), The Analysis of Public Policies in the Arab World, edited by Dr. Salwa Shaarawy Gomaa, Center for Studies and Consultations of Public Administration, Faculty of Economics and Political Science, Cairo University.

Al Ahram (2008), "Egypt signs the global agreement to achieve comprehensive health coverage", available at: http://gate.ahram.org.eg/News/2008634.aspx (accessed 7 October 2018).

Al-Zoghbi, E. (2008), "Attribution to others as an input to improve performance in public service organizations: a comparative study with the Egyptian case", PhD Thesis, Faculty of Economics and Political Science, Department of Public Administration, Cairo University.

Compston, H. (2009), Policy Networks and Policy Change (Putting Policy Network Theory to the Test), Palgrave Macmillan, New York.

El-Shafei, S. (2002), Planning, Design and Installation of Computer Networks, Dar Al-Kuttab Al-Alami for Publishing and Distribution, Cairo.

General Union of Insurance Companies (2013) Recommendations on general effect of comprehensive insurance bill 2013, at the following link": www.ifegypt.org/FAQ.aspx?Page_Id=737 (accessed 14 October 2018).

Gomaa, S. (2004), "Analysis of public policies in the 21st century", in Dr. Salwa Shaarawy Gomaa (Ed.), Public Policy Analysis in the Arab World, Center for Public Administration Studies and Consultations, Cairo.

Gomaa, S. (2015), Pre-Doctoral Lectures, Faculty of Economics and Political Science and Cairo University, Department of Public and Local Management.

Hanafi, K. (2015), "Networks introduction to building strength in the 21st century, supplement to international politics magazine, October".

Ibrahim, M. (2015), "Social security networks and their role in modernizing social insurance system in Egypt”, Master Thesis, Faculty of Economics and Political Science, Department of Economics, Cairo University.

Ministry of Finance (2012), "Partnership unit with the private sector", available at:: www.mof.gov.eg/ Arabic (accessed 20 December 2018).

Ministry of Health (2017), Ministry of health website accessed on 5/12/2017 at the following link", www. mohp.gov.eg (accessed 5 December 2018). 
Rhodes, R.A. (2006), “W, policy network analysis, the oxford handbook of public policy”, Published in the United States by, Oxford University Press Inc., New York, NY.

Ross, K. (2006), Computer Networking: A Top-Down Approach, Addison-Wesley Longman Publishing.

Saleh, M. (2016), "Evaluation of the role of social safety networks in reducing poverty rates in Egypt", $\mathrm{PhD}$ thesis, Faculty of Economics and Political Science, Department of Economics, Cairo University.

Salem, H. (2011), "Partnership between government and private sector as an approach to improving quality in health services: a case study of the health sector in Jeddah and Tabuk, Saudi Arabia", $\mathrm{PhD}$ Thesis, Department of Public Administration, Faculty of Economics and Political Science, Cairo University.

Shteh, N. (2004), "NGOs networks establishment with a comparative study of the arab NGOs network and the global alliance for citizen participation (CIVEX)", Master Thesis, Faculty of Economics and Political Science, Department of Public Administration, Cairo University.

State Information Service (2020), Signed two agreements and 10 declarations of intent on the website at the following link: http://sis.gov.eg/Story/11982 (accessed 20 October 2018).

The World Bank (2018), Project to transform the healthcare system in Egypt, on the website at the following link: www.albankaldawli.org/en/news/press-release/2018 (accessed 27 October 2018).

World Bank (2014), Discussing the importance of comprehensive health coverage on the world bank website at: http://blogs.worldbank.org/voices/en/making-case-universal-health-coverage (accessed 27 October 2018).

World Health Organization (WHO) (2013), Comprehensive coverage research, health report on the WHO website at: www.emro.who.intl (accessed 27 October 2018).

\section{Further reading}

Abd Rabu, A. (2015), "Networks and movements of protests, Arab revolutions model, supplement to the journal of international politics, October.

Abdel-Fattah, H. (1993), Social Health Insurance System as a Protection System, Journal of Health Insurance, Journal of Social Health Insurance, Al-Nabarawi Press.

Al-Zughbi, E. (1998), "Measurement of general satisfaction as an input to the development of public organizations: a case study of the general authority for health insurance", Master Thesis, Faculty of Economics and Political Science, Department of Public Administration, Cairo University.

Al-Husseini, B. (2009), Guide to Cultural Management, Dar Sharqiyat for Publishing and Distribution, Cairo.

Al-Junaidi, N. (2007), "Dual system as an introduction to administrative development: case study of the new kasr Al-Ain teaching hospital", Master Thesis, Department of Public Administration, Faculty of Economics and Political Science, Cairo University.

Al Akhbar (2020), "Minister of health: $\$ 252,000$ cost of updating the actuarial study of the health insurance project", available at: https://akhbarelyom.com/news/newdetails/561500/ (accessed 15 October 2018).

Al Arabiya (2017), Annual conference for investment in healthcare is launched on the website at the following link: www.alarabiya.net/en/aswaq/economy/2017 (accessed 14 January 2018).

Alwani, H. (2001), The Virtual Organization as a New Organizational Structure and Its Implications for Public Administration, Al Nahda Magazine, Faculty of Economics and Political Science.

Aof, A. (2019), "January 7, personal interview".

Anwer, W. (2018), "December 30, personal interview”.

Amain, N. (2018), "December 30, personal interview”.

Botros, M. (1997), "Evaluation of US aid performance in the health sector in Egypt: an empirical study on the expanded program on immunizations", $\mathrm{PhD}$ Thesis, Faculty of Economics and Political Science, Department of Political Science, Cairo University. 
Ebaid, A. (2004), Towards a Comprehensive Economic and Social Structure for the Healthcare Sector in Egypt, Cairo: Public Policy Forum, Center for Public Administration Studies and Consultations, Faculty of Economics and Political Science.

Egyptian Constitution (2014), Articles (18, 167 and 101) ministry of foreign affairs website: accessed on 12/11/2017 at the following link: www.mfa.gov.eg/Arabic/Media (accessed 20 October 2018).

Elshalakani, A. (2018), "November 28, personal interview”.

Galey, S. (2014), Moving towards an Integrated Theory of Policy Networks: A Multi-Theoretical Approach for Examining State-Level Policy Change in U.S. Subsystems, A study in the Education Policy Center at MI State University.

Ghannam, A. (2015), "Road map for Egyptian health system reform and challenges facing Egyptian health system", National Center for Social and Criminal Research, No. 17, Annual Conference

Mattila, M. (1999), The Structure of Policy Networks an Analysis of Political Decision Making Network in Finland, University of Helsinki, Department of Political Science.

Peterson, J. (2003), Policy Networks.Political Science Series, Vienna: Institute for advanced studies.

Qandil, A. (2016), "March 20, personal interview".

Qandil, A. (2003), Role of Arab NGOs in Population Healthcare, Arab Network of NGOs, Cairo.

Schneider, V. (2013), "Policy networks and rationalism", Paper to be presented at the ECPR General Conference in Bordeaux (2013) in the Panel on Policy Networks.

Schneider, V. (2005), Policy-Networks in a Complex Systems Perspective a New Look on an Old Data Set "Information, Exchange and Influence Reputation", University of Constance.

Saad, M. (2018), "January 14, personal interview".

Tom, A.B, Snijders Editors (2016), Multilevel Network Analysis for the Social Sciences Lazega Emmanuel Theory, Methods and Applications, Springer International Publishing Switzerland.

The Egyptian Initiative for Personal Rights (2009), "The right to health committee: draft of health insurance bill tampering with the health of the poor. The committee calls for more equitable ways to finance the new system and warns against the confiscation of the role of the legislative authority for the government on the website of the initiative", available at: https:/eipr.org/press/ 2009/12 (accessed 27 October 2018).

Youm 7 (2013), Minister of health signs a memorandum of intent for health cooperation with Germany on the website at the following link: www.youm7.com/story/2013/2/22/ (accessed 27 October 2018).

Youm 7 (2016), Finance: 10 international organizations confirm their support for the government's efforts to implement health insurance, on the website at the following link: www.youm7.com/ story/2016/1/2 (accessed 27 Oct 2018), https://ar.wikipedia.org/ (accessed 27 Ocober 2018).

Zheng, H., De Jong, M. and Koppenjan, J. (2010), “Applying policy network theory to policy-making in China: the case of urban health insurance reform", Public Administration, Vol. 88 No. 2, available at: https://www.researchgate.net/publication/45796643

\section{Corresponding author}

Hasan Saber can be contacted at: hasanrashad@hotmail.com

For instructions on how to order reprints of this article, please visit our website:

www.emeraldgrouppublishing.com/licensing/reprints.htm

Or contact us for further details: permissions@emeraldinsight.com 